\title{
Horizontal Active Vibration Isolator (HAVI) Using Electromagnetic Planar Actuator (EPA)
}

\author{
Minh-Nha Pham ${ }^{1}$ and Hyeong-Joon Ahn ${ }^{2, t}$
}

1 Department of Mechanical Engineering, School of Advanced Technology, University of Quebec, 1100 Rue Notre-Dame Ouest, Montreal, QC, H3C 1K3, Canada 2 Department of Mechanical Engineering, Soongsil University, 369, Sangdo-ro, Dongjak-gu, Seoul, 156-743, South Korea \# Corresponding Author / E-mail: ahj123@ssu.ac.kr, TEL: +82-2-820-0654, FAX: +82-2-820-0668

KEYWORDS: Horizontal active vibration isolator (HAVI), Flexible beam column (FBC), Electromagnetic planar actuator (EPA)

This paper presents a horizontal active vibration isolator (HAVI) using both horizontal and vertical forces of an electromagnetic planar actuator (EPA). The horizontal force is used to reject horizontal disturbance while the vertical force is applied to adjust natural frequency of the HAVI. A simulation model of the active horizontal isolator with flexible beam column (FBC) is built and active isolation methodology using both horizontal and vertical forces of the EPA is implemented. Simulations and experiments show that PID gain of the HAVI is tuned properly so that the horizontal vibration due to impulse disturbance is reduced by $90 \%$. In addition, vertical force of the EPA can reduce the natural frequency by $40 \%$ for improving its ground isolation performance, compared to horizontal force only.

\section{NOMENCLATURE}

$A_{1-3}=$ approximate dimensionless coefficients for horizontal stiffness of FBC

$c=$ dimensionless damping coefficient

$g=$ dimensionless gravity acceleration

$F_{x, y, z}, f_{x, y, z}=$ dimensionless and dimensionless forces of EPA

$i_{d, q}=$ direct and quadrature currents of EPA

$K f_{x, y, z}=$ dimensionless horizontal and vertical stiffness of FBC

$k_{p}, k_{i}, k_{d}=$ PID gain of controller

$L_{a}, L_{b}=$ length of flexible and rigid parts of FBC

$m=$ dimensionless mass of isolator

$n=$ shape ratio of $\mathrm{FBC}$

$n_{b}=$ number of FBCs

$r_{a, b}=$ radius of flexible and rigid parts of $\mathrm{FBC}$

$z_{g}=$ air gap of EPA

$\delta_{x, z}=$ small dimensionless horizontal and verital deformation of FBC

$\tau=$ magnet pitch

$\lambda_{p m}=$ maximum flux linkage

$\omega_{x, y}(t)=$ dimensionless disturbance

\section{Introduction}

Horizontal active vibration isolator (HAVI) is used to guarantee system performance against the horizontal disturbance such as reaction force due to the acceleration or deceleration of a motion stage. In recent years, active vibration isolators have drawn increasing attention since it possesses several advantages compared to the passive one. The characteristics of different kinds of active vibration isolators have been detailed by many researchers. ${ }^{1-4}$ Simple horizontal vibration isolator with spring-damper-actuator is extended to the multi-degree-of-freedom (MDOF) isolators to satisfy demand of rejection the MDOF disturbance. ${ }^{5}$

Concepts of HAVI are not provided at low cost due to two design challenges: mechanisms and actuator. First, the single-degree-offreedom (SDOF) mechanisms consisted of mass-spring-damper is used widely for vibration isolators. ${ }^{6-8}$ Disturbance from ground can be reduced significantly with very low stiffness. Absorber ${ }^{9}, 10$ is one of methods to reduce vibration. Nevertheless, the absorbers work best only if they are in a limited range and tuned to the exact disturbance frequency. The mass-spring-damper can hardly be applied to MDOF isolator due to the limitation of size and capacity of actuators. Spring aforementioned, a flexible beam column (FBC) is used effectively for vibration isolator mechanisms to take its advantage of providing MDOF motion, adjustable stiffness, precise and linear stiffness. In addition, stiffness of FBC can be adjusted by compression force and 
SDOF vibration isolators with FBC were studied in high-static and low-dynamic stiffness isolator systems. ${ }^{11-15}$

On actuator for horizontal isolators, complex mechanism or large space is necessary since actuator has many limitations such as stroke, degree of freedom and capacity. Although piezoelectric actuators $(\mathrm{PZTs})^{16}$ and voice coil motors (VCMs) ${ }^{17,18}$ are commonly used as actuators, they have limited stroke and provide SDOF. Electromagnetic planar actuators (EPAs) was studied and developed by several authors. A long-stroke planar actuator with a moving magnet provided with a mechanical bearing system was studied. ${ }^{19}$ In addition, a levitation linear motors for lithography was studied. ${ }^{20}$ Furthermore, a magnetic suspension was addressed with a linear controller providing satisfactory performance such as stability and disturbance rejection over a wide range of operating points. ${ }^{21}$ Although 6 DOF EPAs were studied for compact MDOF motion control systems, ${ }^{22-24}$ the EPA was hardly applied to the vibration isolator application.

This paper presents a HAVI using both horizontal and vertical forces of an EPA. In this study, the horizontal force of the EPA rejects horizontal disturbance while the vertical force of the EPA adjusts natural frequency of the isolator. A simulation model of the HAVI is built to tune control gains. Then, active isolation methodology using both horizontal and vertical forces is implemented experimentally. Finally, the effectiveness of the HAVI using the EPA is verified through both simulations and experiments.

\section{Horizontal Active Vibration Isolator (HAVI)}

Fig. 1 shows schematic diagram and photo of the HAVI using an EPA. The HAVI under study consists of two main parts: a passive vibration isolator using FBC and an EPA. Properly designed four FBCs provide substantial MDOF horizontal motion with soft stiffness. In addition, the EPA generates MDOF force for active isolation. The horizontal force regulates horizontal disturbance while the vertical force varies stiffness of the $\mathrm{FBC}$ or natural frequency of the isolator.

\subsection{Non-Dimensional Model of the HAVI}

Mechanism of the horizontal passive vibration isolator (HPVI) using FBCs is shown in Fig. 2(a). The HPVI consists of three main parts: a set of 4 FBCs, a base and a table top to support payload. One free end of each FBC is fastened to the base and the other is attached to the table top. The FBC produces high vertical stiffness but low horizontal stiffness so that the payload moves only in the horizontal direction. (a) Schematic

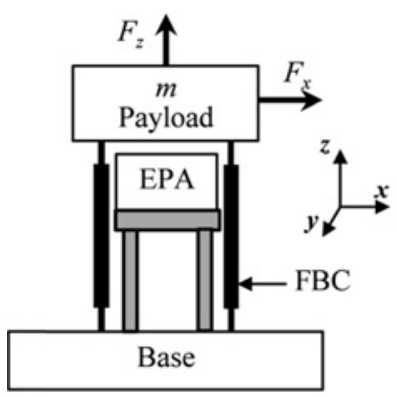

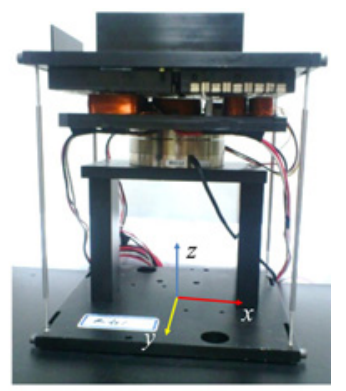

(b) Photograph
Fig. 1 HAVI
The FBC of the HPVI is also illustrated in Fig. 2(a). This column consists of two parts: a rigid (thick) part of length $L_{b}$ and two flexible (thin) parts of length $L_{a}$. Using a non-dimensional analysis, ${ }^{11}$ dimensionless equation of motion for the HPVI can be derived as Eq. (1). Although there is a small vertical parasitic motion due to horizontal motion, the vertical motion is so small to be neglected in this study. Finally, we can obtain a motion equation of the HPVI as shown in Eq. (2).

$$
\begin{gathered}
K f_{x}=K f_{y}=n_{b}\left(A_{1}-A_{2} \frac{m g}{n_{b}}\right) \\
m \ddot{x}+c \dot{x}+K f_{x} x=\omega_{x}(t) \text { and } m \ddot{y}+c \dot{y}+K f_{y} y=\omega_{y}(t)
\end{gathered}
$$

where, $m$ is dimensionless mass, $c$ is dimensionless damping, $n_{b}$ is the total number of FBCs, $A_{1-3}$ are approximate dimensionless coefficients for horizontal stiffness of the FBC, which are functions of only shape ratio of FBC $\left(n=L_{b} / L_{a}\right)$ :

$$
\begin{aligned}
& A_{1}=\frac{6}{3 n^{2}+6 n+4} ; A_{2}=\frac{3 n+2}{3 n^{2}+6 n+4}+\frac{8}{5\left(3 n^{2}+6 n+4\right)^{2}} ; \\
& A_{3}=\frac{3 n+2}{2\left(3 n^{2}+6 n+4\right)}+\frac{4}{5\left(3 n^{2}+6 n+4\right)^{2}}
\end{aligned}
$$

Equations above show various benefits of the FBC structure for horizontal vibration isolator. First, the FBC provides MDOF motion of both translational and rotational directions. Second, the FBC has linear stiffness and changes under the compression force $(m g)$.

The HPVI can be modelled as mass-spring-damper, as shown in Fig. 2(b) since small material damping of the FBC is introduced and will be determined experimentally. Specifications of the FBC are shown in Table 1. Here, $r_{a}$ and $r_{b}$ are the radius of flexible and rigid parts of the FBC.

\subsection{EPA}

Schematic diagram of the EPA is shown in Fig. 3. The stator has 4 coil arrays and moving stage has four 1-D Halbach magnet arrays. The EPA in this study is the combination of four 1-D actuators as shown in Fig. 3(a). Each 1-D actuator consists of 1-D Halbach magnet array and the corresponding coil array and its structure is shown in Fig. 4. The EPA provides a notable benefit of compact size (its thickness is just $35 \mathrm{~mm}$ ) that is comparable to PZM. MDOF forces of the EPA enable motion control of the moving stage in $x$ and $y$ directions and rotation around $z$ direction.

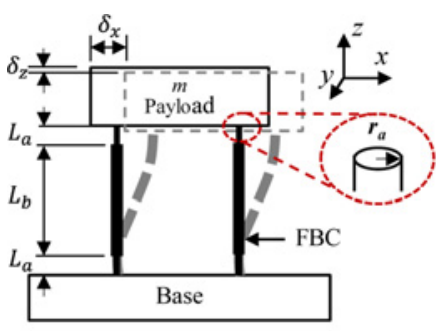

(a) HPVI

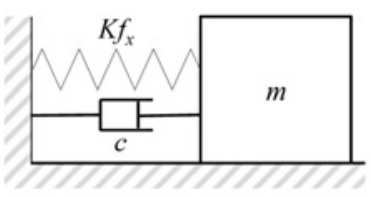

(b) Simplified model in $x$ direction
Fig. 2 HPVI using FBCs

Table 1 FBC parameters

\begin{tabular}{cccc}
\hline Parameter & Value & Parameter & Value \\
\hline$L_{a}$ & $25(\mathrm{~mm})$ & $r_{a}$ & $1.15(\mathrm{~mm})$ \\
\hline$L_{b}$ & $110(\mathrm{~mm})$ & $r_{b}$ & $2(\mathrm{~mm})$ \\
\hline$n_{b}$ & 4 & Material & SUV6 \\
\hline
\end{tabular}


The EPA is designed based on an ideal linear three-phase synchronous motor. Its specifications are shown in Table 2. Horizontal and vertical forces of the EPA can be derived as Eq. (3) using electromagnetic analysis and DQ transformation. ${ }^{16}$

$$
\left[\begin{array}{l}
F_{x} \\
F_{z}
\end{array}\right]=\left[\begin{array}{l}
\frac{3}{2} \frac{\pi}{\tau} \lambda_{p m} \exp \left(-\frac{\pi}{\tau} Z_{g}\right) i_{q} \\
-\frac{3}{2} \frac{\pi}{\tau} \lambda_{p m} \exp \left(-\frac{\pi}{\tau} Z_{g}\right) i_{d}
\end{array}\right]
$$

where, $\lambda_{p m}$ is maximum flux linkage, $z_{g}$ is the air gap between the magnet and the coil arrays in $z$ direction, $\tau$ is the distance between $\mathrm{S}$ and $\mathrm{N}$ poles of the magnet array.

\subsection{HAVI Using the EPA}

Dimensionless motion equations of the HAVI using the EPA are derived as Eqs. (4) and (5). In this paper, only translational motion of the isolator is considered for simplicity.

$$
\begin{aligned}
& m \ddot{x}+c \dot{x}+n_{b}\left(A_{1}-A_{2} \frac{m g+f_{z}}{n_{b}}\right) x=\Sigma f_{x}+\omega_{x}(t) \\
& m \ddot{y}+c \dot{y}+n_{b}\left(A_{1}-A_{2} \frac{m g+f_{z}}{n_{b}}\right) y=\Sigma f_{y}+\omega_{y}(t)
\end{aligned}
$$

Here, $f_{x}, f_{y}$ and $f_{z}$ are dimensionless forces of the EPA.

\section{Simulation}

\subsection{Model Validation of the HPVI}

Simulation model of the HPVI is built based on Eqs. (5) and (6) and verified with the EPA. Specifications of the isolator are given in Table 3. Both

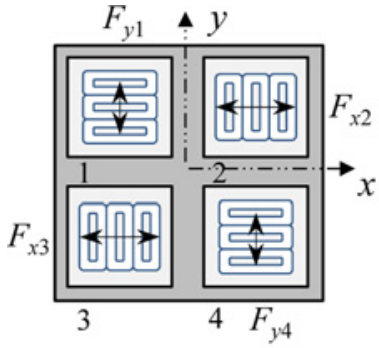

(a) Upper view

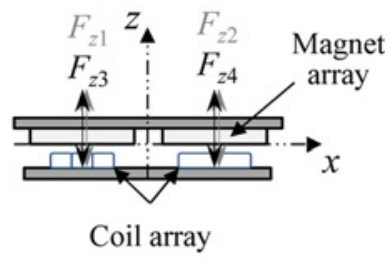

(b) Side view
Fig. 3 EPA configuration and force generation

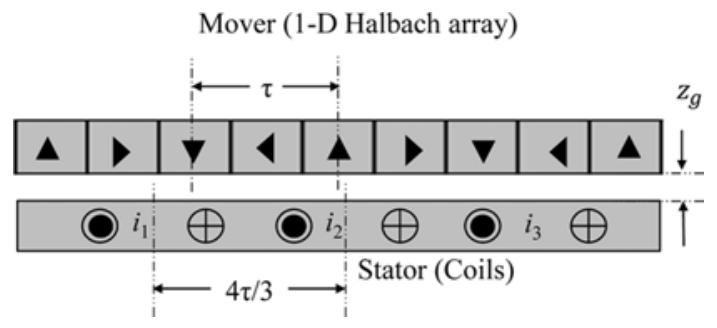

Fig. 4 1-D actuator configuration

Table 2 EPA parameters

\begin{tabular}{cccc}
\hline Parameter & Value & Parameter & Value \\
\hline Max flux linkage & $1.25(\mathrm{~T})$ & Stroke & $\pm 10(\mathrm{~mm})$ \\
\hline Pitch $(\tau)$ & $14.5(\mathrm{~mm})$ & Air gap & $2.4(\mathrm{~mm})$ \\
\hline
\end{tabular}

simulation and experimental responses in time and frequency domains are shown in Fig. 5. The simulation model matches well with experimental data.

\subsection{HAVI Using the EPA}

A simulation model for the HAVI using the EPA is built as shown in Fig. 6. The simulation model consists of the HPVI, the EAP and a controller. The controller includes four PIDs for each magnet array, input of vertical force with direct currents and DQ transformation.

PD control gains $\left(k_{p}\right.$ and $k_{d}$ ) for the HAVI are determined considering both settling time against disturbance and maximum coil current including $d$ and $q$ axis currents $\left(i_{d}\right.$ and $i_{q}$ ), as shown in Fig. 7. Basically, settling time of the HAVI decreases dramatically as the derivative gain increases rather than the proportional gain, as shown in Fig. 7(a). The increased derivative gain causes the large quadrature current, as described in Fig. 7(b). However, total coil current with both $i_{q}$ and $i_{d}$ should be within $2 \mathrm{~A}$, as shown in Fig. 7(c). As we set $k_{d}$ of 0.03 to balance horizontal and vertical forces, maximum $i_{q}$ is $1.1 \mathrm{~A}$ from Fig. 7(c) and $i_{d}$ for a coil array may flow up to 1.5 A from Fig. $7(\mathrm{c})$. Since we have four coil arrays, the static current for vertical force is four times $i_{d}(=6 \mathrm{~A})$.

Table 3 Parameters of the HPVI

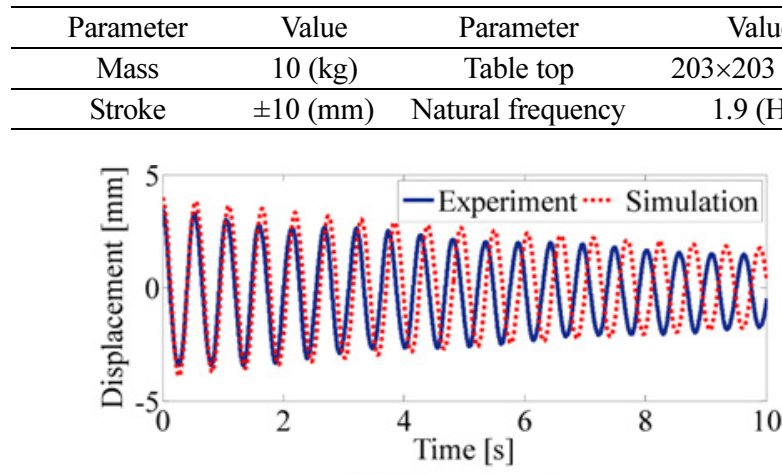

(a) Time domain

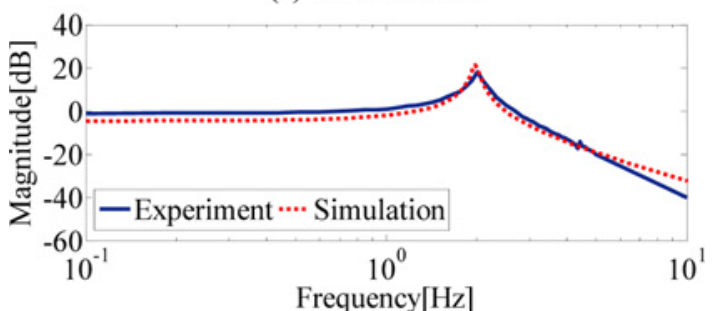

(b) Frequency domain

Fig. 5 Model validation of the HPVI

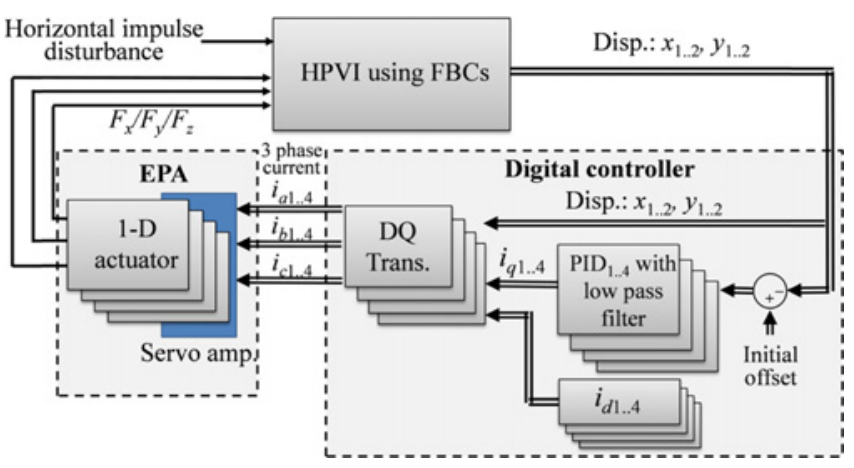

Fig. 6 Simulation model of HAVI 
For various $\mathrm{D}$ gains and zero direct current $\left(i_{d}\right)$, horizontal displacement and quadrature current of the HAVI to impulse disturbance as well as frequency response of the HAVI are simulated and shown in Fig. 8. The HAVI using the EPA rejects the impulse disturbance effectively.

For various direct current $\left(i_{d}\right)$ and fixed D gains $\left(k_{d}=0.03\right)$, horizontal impulse responses and frequency responses of the HAVI are

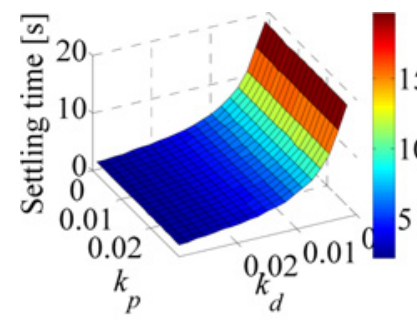

(a) Settling time

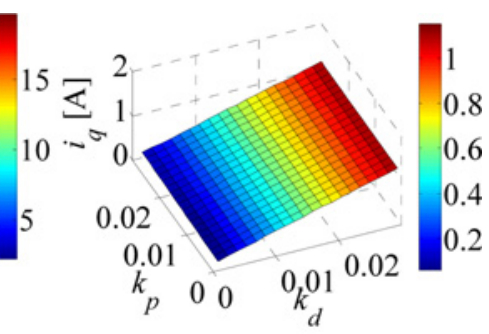

(b) Current $i_{q}$

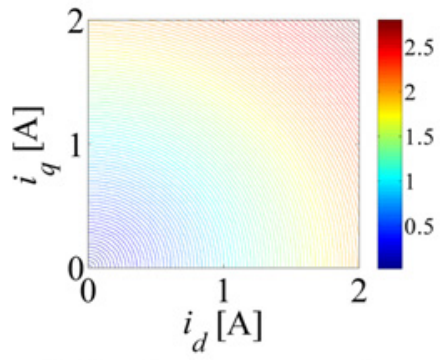

(c) Absolute current on coil

Fig. 7 PD gains considering settling time and maximum coil current

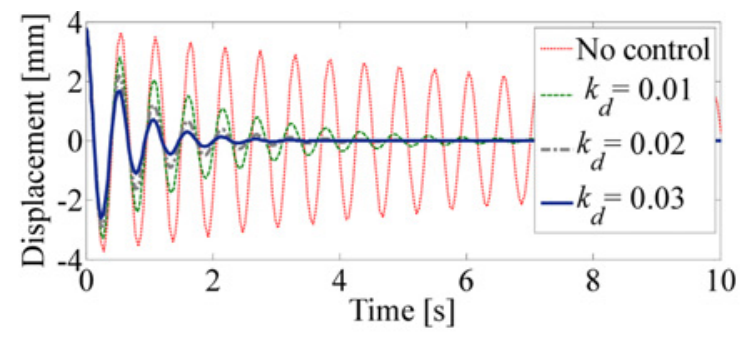

(a) Displacement in time domain

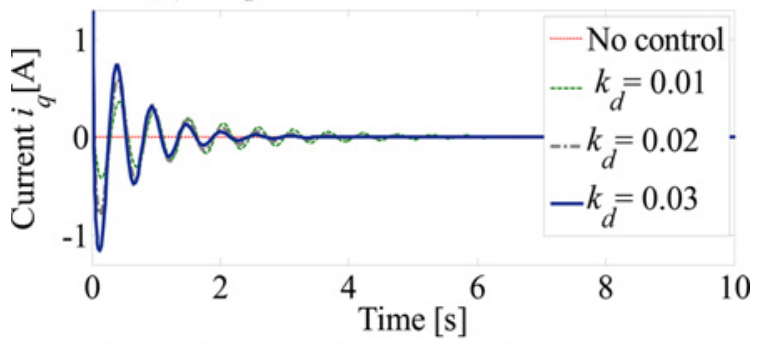

(b) Quadrature $\left(i_{q}\right)$ current in time domain

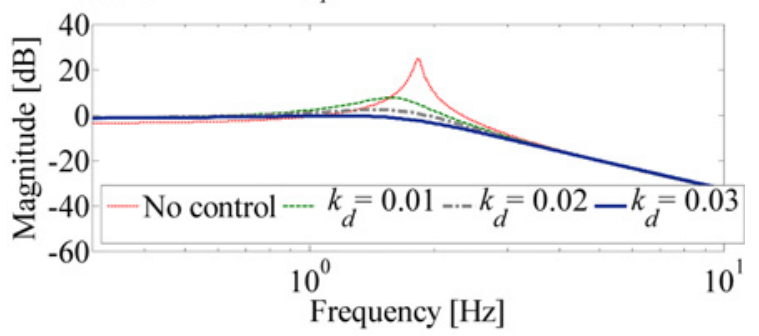

(c) Frequency response

Fig. 8 Simulation of the HAVI using the EPA with various D gains and zero direct current simulated, as shown in Fig. 9. The vertical forces using direct currents reduce the horizontal stiffness of HAVI.

\section{Experiment}

A schematic for experimental set-up of the HAVI using the EPA is shown in Fig. 10. The experiment setup consists of a HPVI with FBCs, the EPA, a digital controller, hall sensor arrays, and amplifiers. A digital controller (dSPACE DS1104) is used to implement PID control and to adjust the direct current. Four hall sensor arrays are used to measure MDOF motion of the HAVI. ${ }^{25}$

The impulse disturbance rejection is investigated experimentally to verify effectiveness of the HAVI using the EPA. For various D gains ( $k_{p}=0.03$ and $k_{i}=0.01$ ) and zero direct current, experimental impulse response of horizontal displacement and quadrature current of the HAVI using the EPA are shown in Fig. 11. The settling time of the HAVI with $k_{d}=0.03$ is reduced significantly (around $90 \%$ ) compared to the HPVI. Frequency responses of the HPVI, HAVI with and without

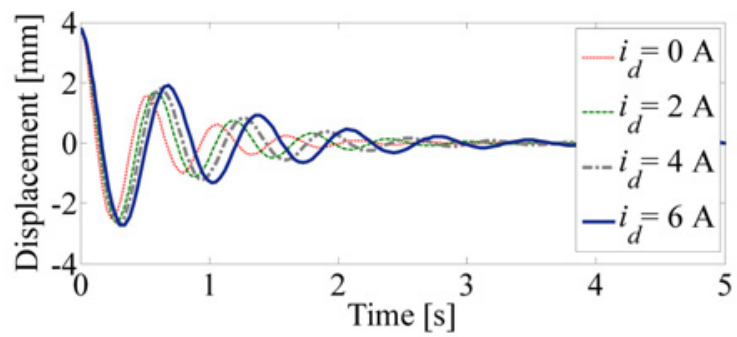

(a) Time domain

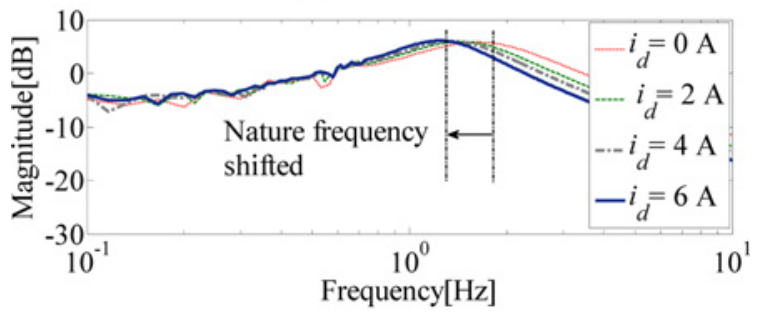

(b) Frequency domain

Fig. 9 Simulation of the HAVI using the EPA with various direct currents and fixed D gain

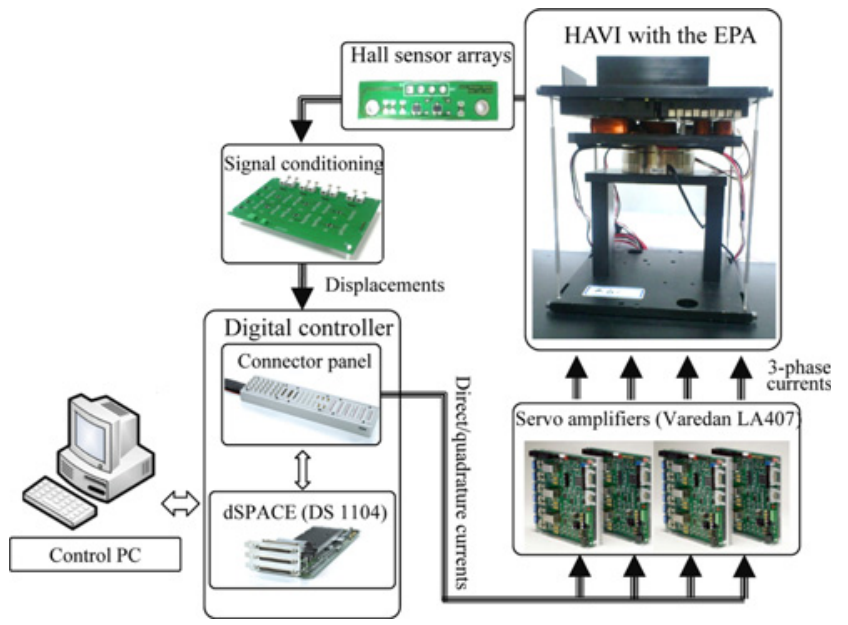

Fig. 10 Schematic for experimental set-up of the HAVI 
direct current are measured experimentally and shown in Fig. 12. With the static direct current of 6A, the natural frequency of the HAVI is lowered by $40 \%$ compared to the HPVI and the HAVI without direct current.

\section{Conclusions}

This paper presents HAVI using both horizontal and vertical forces of an EPA. The HAVI mainly consist of a HPVI with FBCs and the EPA. The EPA is composed of a stator with coil arrays and a mover with four 1-D Halbach magnet arrays. Based on DQ decomposition, a model of the EPA is built by combining four 1-D actuators. Equation of motion for the HAVI is obtained by combining both dynamic models of the HPVI with FBCs and the EPA, which is verified with experiments. PID gains are tuned considering settling time of the HAVI as well as allowed coil current so that the HAVI using the EPA reduces a horizontal impulse response by $90 \%$ compared to the HPVI. In addition, horizontal disturbance rejection from ground is improved by reducing the natural frequency of the HAVI using the vertical force due to direct current of the EPA, which is about $40 \%$ reduction compared to HPVI and the HAVI without vertical force or direct current.

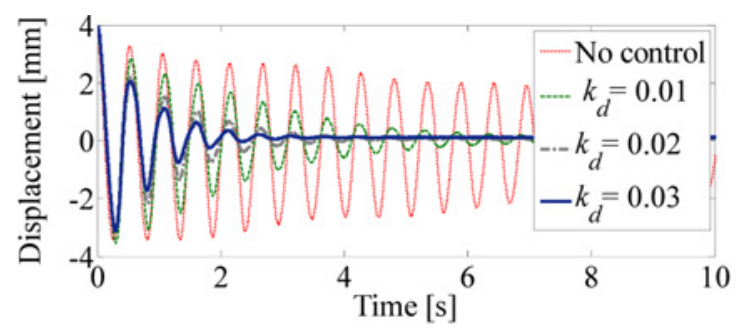

(a) Displacement

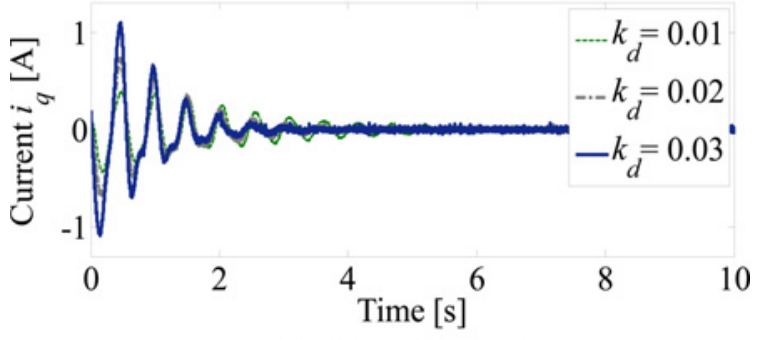

(b) Control current

Fig. 11 Experimental impulse responses of the HAVI using the EPA

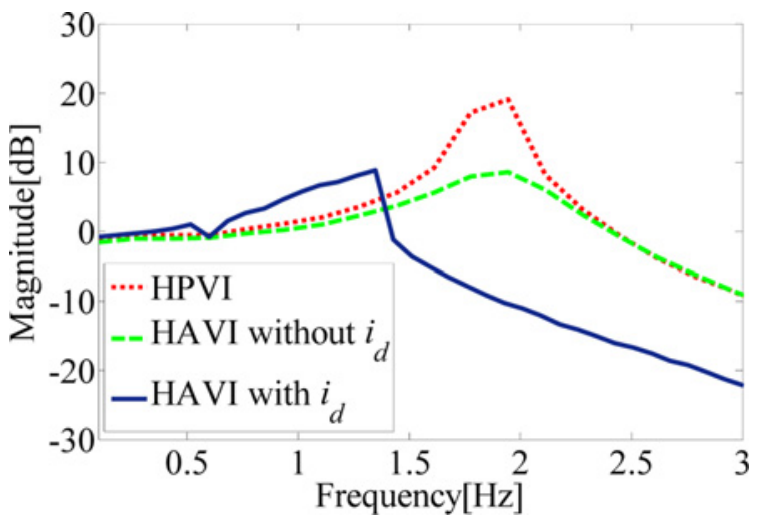

Fig. 12 Experimental frequency responses of the HPVI, HAVI with and without direct current

\section{ACKNOWLEDGEMENT}

This research was supported by the MSIP (Ministry of Science, ICT \& Future Planning), Korea, under the C-ITRC (Convergence Information Technology Research Center) (IITP-2015-H8601-15-1001) supervised by the IITP (Institute for Information \& communications Technology Promotion) and by Basic Science Research Program through the National Research Foundation of Korea (NRF) funded by the Ministry of Education, Science and Technology (NRF2013R1A1A2010764).

\section{REFERENCES}

1. Watters, B. G., Coleman, R. B., Duckworth, G. L., and Berkman, E. F., "A Perspective of Active Machinery Isolation," Proc. of the $27^{\text {th }}$ IEEE Conference on Decision and Control, Vol. 3, pp. 2033-2038, 1988.

2. Crosby, M. J. and Karnopp, D. C., "The Active Damper - A New Concept for Shock and Vibration Control," Shock and Vibration Bulletin, Vol. 43, pp. 119-133, 1973.

3. Jenkins, M. D. and Nelson, P. A., "Active Isolation of Periodic Machinery Vibration from Resonant Substructures," Journal of Environmental Engineering, Vol. 4, No. 3, pp. 6-11, 1991.

4. Karnopp, D. C., Crosby, M. J., and Harwood, R. A., "Vibration Control Using Semi-Active Force Generators," Journal of Manufacturing Science and Engineering, Vol. 96, No. 2, pp. 619-626, 1974.

5. Nelson, F. C., "Vibration Isolation: A Review, I. Sinusoidal and Random Excitations," Shock and Vibration, Vol. 1, No. 5, pp. 485493, 1994

6. Harris, C. M. and Crede, C. E., "Shock and Vibration Handbook," $3^{\text {rd }}$ Ed., McGraw Hill, 1988.

7. Snowdon, J. C., "Isolation and Absorption of Machinery Vibration," Acta Acustica United with Acustica, Vol. 28, No. 6, pp. 307-317, 1973.

8. Miller, L. R., "Tuning Passive, Semi-Active and Fully Active Suspension Systems," Proc. of the $27^{\text {th }}$ IEEE Conference on Decision and Control, Vol. 3, pp. 2047-2053, 1988.

9. Meirovitch, L., "Elements of Vibration Analysis," $2^{\text {nd }}$ Ed., McGraw Hill, 1986.

10. Inman, D. J., “Engineering Vibration,” Prentice-Hall, 1996.

11. Pham, V. T., Kim, K. R., and Ahn, H. J., "A Nonlinear Control of a QZS Isolator with Flexures Based on a Lyapunov Function,” Int. J. Precis. Eng. Manuf., Vol. 14, No. 6, pp. 919-924, 2013.

12. Kim, K. R., You Y. H., and Ahn, H. J., "Optimal Design of a QZS Isolator Using Flexures for a Wide Range of Payload,” Int. J. Precis. Eng. Manuf., Vol. 14, No. 6, pp. 911-917, 2013.

13. Huang, X., Liu, X., Sun, J., Zhang, Z., and Hua, H., "Vibration Isolation Characteristics of a Nonlinear Isolator Using Euler Bucked Flexible Beam as Negative Stiffness Corrector: A Theoretical and Experimental Study," Journal of Sound and Vibration, Vol. 333, No. 4, pp. 1132-1148, 2014. 
14. Tang, B. and Brennan, M. J., "On the Shock Performance of a Nonlinear Vibration Isolator with High-Static-Low-DynamicStiffness," International Journal of Mechanical Sciences, Vol. 81, pp. 207-214, 2014.

15. Shin, K., "On the Performance of a Single Degree-of-Freedom High-Static-Low-Dynamic Stiffness Magnetic Vibration Isolator," Int. J. Precis. Eng. Manuf., Vol. 15, No. 3, pp. 439-445, 2014.

16. Chang S. H., Tseng C. K., and Chien H. C., “An Ultra-Precision XYz Piezo-Micropositioner Part I: Design and Analysis," IEEE Transactions on Ultrasonics, Ferroelectrics, and Frequency Control, Vol. 46, No. 4, pp. 897-905, 1999.

17. Shinno, H., Yoshioka, H., and Taniguchi, K., “A Newly Developed Linear Motor-Driven Aerostatic X-Y Planar Motion Table System for Nano-Machining," CIRP Annals - Manufacturing Technology, Vol. 56, No. 1, pp. 369-372, 2007.

18. Hong, D. P., Hwang, H. Y., Lee, M. Y., Jo, Y. K., Vu, D. T., et al., "New Electro-Magnetic Actuator for Active Vibration Isolators," Int. J. Precis. Eng. Manuf., Vol. 16, No. 1, pp. 209-212, 2015.

19. Compter, J. C. and Frissen, P. C. M, "Electro-Dynamic Planar Actuator," Proc. of Mechatronics, pp. 81-87, 2002.

20. Trumper, D. L., "Magnetic Suspension Techniques for Precision Motion Control," Ph.D. Thesis, Department of Electrical Engineering and Computer Science, Massachusetts Institute of Technology, 1990.

21. Trumper, D. L., Olson, S. M., and Subrahmanyan, P. K., "Linearizing Control of Magnetic Suspension Systems," IEEE Transactions on Control Systems Technology, Vol. 5, No. 4, pp. 427438, 1997.

22. Van Lierop, C. M. M., Jansen, J. W., Damen, A. A. H., and van den Bosch, P. P. J., "Control of Multi-Degree-of-Freedom Planar Actuators," IEEE International Symposium on Intelligent Control, pp. 2516-2521, 2006.

23. Kim, W., Hu, T., and Bhat, N. D., "Design and Control of a 6-DOF High-Precision Integrated Positioner," Proc. of the American Control Conference, pp. 2493-2498, 2004.

24. Lu, X., Rao, N., and Usman, I. U. R., "Six-Axis Position Measurement System for Levitated Motion Stages," CIRP Annals Manufacturing Technology, Vol. 62, No. 1, pp. 507-510, 2013.

25. Ahn, H. J. and Kim, K. R., "2D Hall Sensor Array for Measuring the Position of a Magnet Matrix,” Int. J. Precis. Eng. Manuf.-Green Tech., Vol. 1, No. 2, pp. 125-129, 2014. 